\title{
STUDI PERBANDINGAN ANIMASI 360 DERAJAT BERTEMA SEJARAH
}

\section{Arif Sutrisno}

\author{
(Game Animasi)-Seni dan Desain Universitas Negeri Malang \\ Email: arif.sutrisno.fs@um.ac.id
}

\begin{abstract}
To identify general characteristics of historical-themed $360^{\circ}$ animation, visual characteristics, and ways of delivering material in historical learning media, this study attempts to compare three historical-themed $360^{\circ}$ animations, namely the game trailer Assassin's Creed Syndicate Jack the Ripper, Dinosaurs World 360 VR, and Dunkirk 'Save Every Breath'. This research method is to determine the benchmark focus, planning and research, data collection, implementation, recommendations, and analysis. In general, historical $360^{\circ}$ animation uses 3D animation techniques. The flow used tends to be linear with narrative storytelling. The point of view used is first person. The camera movement used is the following subject.
\end{abstract}

Keywords: Animation 360 Degree, Learning Media, History

\begin{abstract}
Abstrak: Untuk mengidentifikasi karakteristik umum animasi $360^{\circ}$ bertema sejarah serta mengidentifikasi karakteristik visual dan cara penyampaian materi yang sesuai untuk media pembelajaran sejarah maka studi ini berusaha membandingkan tiga animasi $360^{\circ}$ bertema sejarah yaitu trailer game Assassin's Creed Syndicate - Jack the Ripper, Dinosaurs World 360 VR, dan Dunkirk 'Save Every Breath'. Metode penelitian ini adalah dengan menentukan benchmark focus, perencanaan dan riset, pengumpulan data, implementasi, rekomendasi, dan terakhir analisis. Secara umum, animasi sejarah $360^{\circ}$ menggunakan teknik animasi 3D. Alur yang digunakan cenderung linier dengan narrative storytelling. Sudut pandang yang digunakan adalah orang pertama. Pergerakan kamera yang digunakan adalah follow subject.
\end{abstract}

Kata kunci: Animasi 360 Derajat, Media Pembelajaran, Sejarah

\section{LATAR BELAKANG}

Sejarah merupakan salah satu pelajaran yang memiliki nilai penting dalam membangun sikap dan jiwa sosial seorang pelajar. Dalam tingkatan Sekolah Dasar, sejarah terintegrasi dalam satuan mata pelajaran IPS. Salah satu tujuan mata pelajaran sejarah dalam Permendiknas no. 22 tahun 2006 (melalui Sayono, 2013, pp. 12-13) adalah menumbuhkan pemahaman siswa terkait proses pembentukan Bangsa Indonesia melalui peristiwa yang panjang. Dengan mempelajari peristiwa kesejarahan, siswa akan mengetahui nilainilai sosial yang tumbuh dalam perkembangan kebudayaan dalam kemasyarakatan serta mengambil pelajaran dari peristiwa tersebut. Misalnya dengan memahami faktor-faktor sosial runtuhnya sebuah kebudayaan di

Received on $\quad: 14 / 02 / 2021$

Revised on :03/03/2021

Accepted on : 24/03/2021
Indonesia, hal ini bisa dijadikan acuan sikap yang perlu ditiru atau dihindari sehingga masalah tersebut tidak datang kembali di masa yang akan datang.

Proses pembelajaran sejarah sangat bergantung dengan adanya media pembelajaran. Tanpa adanya media, siswa akan terjebak dalam imajinasi-imajinasi yang membuat peristiwa sejarah semakin abstrak. Misalnya melalui media film animasi. Film animasi mampu mengilustrasikan peristiwa-peristiwa sejarah yang abstrak menjadi lebih nyata. Model visualisasi film animasi tidak terbatas sehingga kontennya sangat adaptif terhadap kebutuhan dan kesesuaian karakteristik peserta didik. Hal ini juga yang membuat film animasi cenderung lebih menarik sebagai media belajar sejarah. Hal ini juga didukung dengan 
hasil penelitian dari Agustien dkk (2018, p. 22). Dalam penelitian tersebut, media berupa video animasi mampu meningkatkan daya tarik siswa dan kualitas pembelajaran sejarah.

Akhir-akhir ini teknologi virtual reality cukup populer. Virtual reality adalah media yang memproyeksikan lingkungan virtual ke dalam sudut pandang $360^{\circ}$. Menurut statista.com (melalui Jamil, 2018, p. 104) pengguna aktif virtual reality dari tahun 2014 - 2018 diperkirakan mencapai 171 juta dan akan tumbuh signifikan di tahun-tahun mendatang. Potensi ini tentunya juga akan mempengaruhi perkembangan media pembelajaran khususnya di bidang sejarah. Melihat karakteristik virtual reality sebagai media pembelajaran sejarah, maka penggambaran peristiwa sejarah akan semakin imersif. Hal ini karena siswa seolah dapat dihadirkan langsung ke lokasi terjadinya sejarah melalui film animasi $360^{\circ}$. Adanya media pembelajaran sejarah berbasis animasi $360^{\circ}$ akan meningkatkan efektivitas proses pembelajaran sejarah.

Perancangan merupakan aktivitas membuat usulan-usulan atau konsepkonsep yang mengubah sesuatu yang telah ada menjadi lebih baik (Sukmawati dan Susiano, 2019:61). Proses perancangan adalah proses perubahan sesuatu dari kondisi awal menuju kondisi masa berikutnya yang ada di bayangan seorang desainer dan menjelaskan berbagai aktivitas di dalamnya. Proses perancangan tidak bisa berdiri sendiri melainkan berangkat dari objek-objek ataupun penelitian-penelitian yang sudah ada sebelumnya. Dalam hal ini sebelum merancang pembelajaran animasi $360^{\circ}$ bertemakan sejarah, maka perlu adanya studi banding dari animasi-animasi $360^{\circ}$ bertemakan sejarah yang sudah ada sebelumnya.

Studi perbandingan adalah proses menganalisa dua hal atau lebih untuk mencari kesamaan-kesamaan dan perbedaan-perbedaannya. Dengan demikian maka studi perbandingan ini mengandung pengertian sebagai usaha menganalisa dan mempelajari secara mendalam dua hal atau aspek dari objek desain, untuk mencari dan menemukan kesamaan-kesamaan dan perbedaanperbedaan yang ada dari kedua hal tersebut sehingga ditemukan rekomendasirekomendasi yang bisa digunakan untuk proses perancangan berikutnya.

Oleh karena itu, untuk mengidentifikasi karakteristik umum animasi $360^{\circ}$ bertema sejarah dan mengidentifikasi karakteristik visual dan cara penyampaian materi yang sesuai untuk media pembelajaran sejarah maka studi ini berusaha membandingkan tiga animasi $360^{\circ}$ bertema sejarah yaitu trailer game Assassin's Creed Syndicate - Jack the Ripper, Dinosaurs World 360 VR, dan Dunkirk 'Save Every Breath'. Tujuan penelitian ini adalah untuk mengidentifikasi karakteristik umum animasi 360 o bertema sejarah serta karakteristik visual dan cara penyampaian materi yang sesuai untuk media pembelajaran sejarah.

\section{ANIMASI 360 DERAJAT}

Film yang diproduksi dalam VR memungkinkan penonton melihat lingkungan 360 derajat di setiap adegan. Perusahaan produksi, seperti Fox Searchlight Pictures dan Skybound, memanfaatkan kamera VR untuk memproduksi film dan seri yang interaktif di VR (Cieply, 2016).

Realitas virtual dalam fiksi menggambarkan representasi fiktif dari konsep teknologi VR. Banyak buku dan film fiksi ilmiah yang membawa karakter ke dalam dunia virtual. Buku ini telah menghadirkan gagasan tentang realitas maya sebagai substitusi parsial, namun tidak total, untuk kesengsaraan realitas, atau telah disebut-sebut sebagai metode untuk menciptakan dunia maya dimana orang dapat melarikan diri dari Bumi.

Scene dalam Animasi 3D biasanya mengandung objek statis yang dikelompokkan menjadi hiasan dan objek animasi yang terus berubah berdasarkan hukum gerak. Selain itu, adegan dilihat menggunakan kamera virtual dan mungkin diterangi oleh sumber cahaya sintetis. Kamera dan lampu ini terus berubah seiring waktu seolah dimanipulasi oleh 
kameramen. Untuk menciptakan semua entitas dan gerakan, mengkoordinasikan dan menyinkronkannya dikenal istilah koreografi. Hal ini perlu dilakukan untuk mengetahui kemunculan scene saat ini dan kemudian dengan teknik CG memungkinkan kita untuk membangun dan menampilkan scene sesuai dengan viewing dan parameter lighting.

Virtual reality mampu memberikan sensasi menikmati sebuah cerita yang lebih baik dibandingkan media digital lainnya. Hal ini disebabkan oleh faktor immersion yang membuat seolah user benar-benar berada di ruang dan waktu yang sama dengan kejadian yang sedang berlangsung dalam cerita. Faktor ini tentunya membuat user bisa lebih dekat dengan karakter serta konflik yang sedang dialaminya sehingga empati akan lebih kuat dibandingkan menonton dari layar. Immersive dalam virtual reality adalah konsep teknologi masa depan yang muncul di zaman ini dan secara garis besar berupa proyek seni dalam realitas maya (Nechvatal, 2009, pp. 367-368).

Selain itu faktor presence juga membuat user bisa lebih ikut terlibat dalam situasi yang dialami karakter. Edward Saatchi, produser dari Oculus Story Studio (melalui Nelson, 2015) mendeskripsikan presence dalam virtual reality sebagai merasakan adanya tubuh (sosok tertentu), perasaan jiwa dan pikiran, yang berada di suatu tempat yang sebenarnya tidak ada. Dalam animasi virtual reality Henry, presence dari user coba dihadirkan melalui kontak mata karakter yang sesekali melihat ke arah user. Presence semacam ini mampu membuat interaksi pandangan yang melibatkan user sehingga user bisa terbawa lebih jauh ke dalam cerita.

Dalam storytelling melalui virtual reality, penetapan point of view (sudut pandang) dan perspektif perlu dipertimbangkan. Misalnya pada adegan pembunuhan, sudut pandang user sebagai orang pertama menjadi pembunuhnya. Maka perspektif yang akan muncul adalah nuansa ketakutan dari korbannya. Sebaliknya, ketika user dengan sudut pandang orang pertama sebagai korbannya, maka perspektif yang akan muncul adalah nuansa sadis pembunuh yang mengerikan. Namun, ketika user dalam sudut pandang orang ketiga dengan perspektif melihat adegan pembunuh membunuh korbannya, status user harus jelas. Apakah user menjadi salah satu orang yang menjadi saksi pembunuhan tersebut, atau apakah user menjadi sosok tidak bertubuh yang menyaksikan adegan pembunuhan tersebut. Hal semacam ini menjadi sangat penting untuk diperhatikan mengingat adanya presence user dalam animasi virtual reality.

Immersion dalam virtual reality adalah persepsi akan hadirnya fisik di dalam dunia non fisik. Persepsi itu tercipta dengan membuat user VR dikelilingi oleh gambar, suara atau rangsangan lainnya yang memberikan pengalaman mengesankan dalam lingkungan 360 derajat.

Immersion merupakan penggunaan metafora dari larutnya pengalaman yang diaplikasikan dalam representasi, fiksi, ataupun simulasi. Immersion juga dapat didefinisikan sebagai tingkat kesadaran visitor atau immersant terhadap kehadiran sosok fisiknya yang ditransformasikan ke dalam dunia buatan, digunakan untuk menggambarkan suspensi sebagian atau keseluruhan dari ketidakpercayaan, memungkinkan aksi atau reaksi terhadap rangsangan yang diterima dalam lingkungan buatan tersebut. Tingkat kedalaman immersion ini ditentukan oleh tingkat seberapa meyakinkannya lingkungan buatan tersebut dihadirkan. Semakin meyakinkan dunia virtual yang dibangun, maka semakin tinggi pula kehadiran sosok yang dirasakan user.

Menurut Ernest W. Adams (2004), penulis dan konsultan game design, immersion bisa dibedakan ke dalam 3 pokok kategori yaitu:

1. Tactical Immersion

Tactical immersion dialami saat terjadi interaksi berupa taktil yang melibat keterampilan user. User merasuk dalam zonanya sambil menyempurnakan aksinya hingga membuatnya berhasil memecahkan masalah.

2. Strategic Immersion

Strategic immersion cenderung lebih melibatkan otak dan terkait dengan 
tantangan secara mental. Pemain catur mengalami strategic immersion ketika memilih pemecahan masalah yang tepat di antara berbagai kemungkinan yang bisa terjadi.

\section{Narrative Immersion}

Narrative immersion terjadi saat user larut ke dalam sebuah cerita. Hal ini seperti yang dialami saat membaca buku cerita atau menonton film.

\section{METODE}

Dalam studi perbandingan ini pertama-tama langkah yang dilakukan adalah menentukan benchmark focus. Hal ini bertujuan untuk menentukan kriteria penilaian yang disesuaikan dengan tujuan dari studi perbandingan ini sehingga aspek penilaian bisa lebih fokus dan sesuai. Langkah berikutnya adalah perencanaan dan riset untuk menentukan cara mendapatkan data. Selanjutnya mulai mengumpulkan data yang berhubungan dengan studi perbandingan ini dan mulai menganalisis data-data tersebut. Dari hasil analisis akan ditemukan rekomendasirekomendasi yang bisa dijadikan aspek penentuan untuk rancangan berikutnya. Dari rekomendasi ini kemudian diimplementasikan ke dalam objek rancangan selanjutnya.

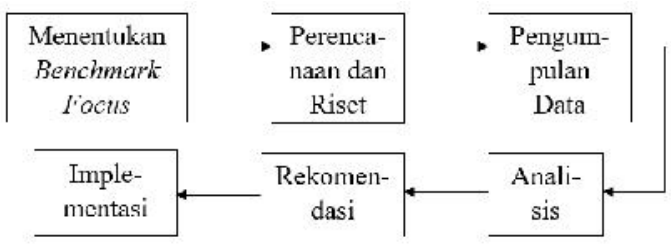

Gambar 1. Metode perbandingan

\section{HASIL PERBANDINGAN}

1. Benchmark Focus

$\begin{array}{ll}\text { a. } & \text { Pergerakan Karakter } \\ \text { b. } & \text { Ekspresi Karakter } \\ \text { c. } & \text { Sinematografi } \\ \text { d. } & \text { Storytelling } \\ \text { e. } & \text { Simulasi } \\ \text { f. } & \text { Daya Tarik } \\ \text { g. } & \text { Kejelasan } \\ \text { h. } & \text { Immersion } \\ \text { i. } & \text { Membangun Emosi } \\ \text { j. } & \text { Kesesuaian }\end{array}$

2. Perencanaan dan Riset

Dalam tahap perencanaan dan riset ini dilakukan penentuan metode pengumpulan data. Data-data digali melalui cara observasi dan studi literatur. Observasi bertujuan melihat gambaran nyata data langsung di lapangan. Dalam hal ini berarti mengamati ketiga objek perbandingan yaitu Assassin's Creed Syndicate - Jack the Ripper, Dinosaurs World 360 VR, dan Dunkirk 'Save Every Breath'. Studi literatur berguna untuk menggali informasi yang dibutuhkan baik dari penelitian terdahulu maupun teoriteori yang telah dikembangkan.

3. Pengumpulan Data

Dari hasil observasi dan studi literatur, maka ditemukan data-data objek perbandingan seperti berikut ini.

a. Assassin's Creed Syndicate Jack the Ripper

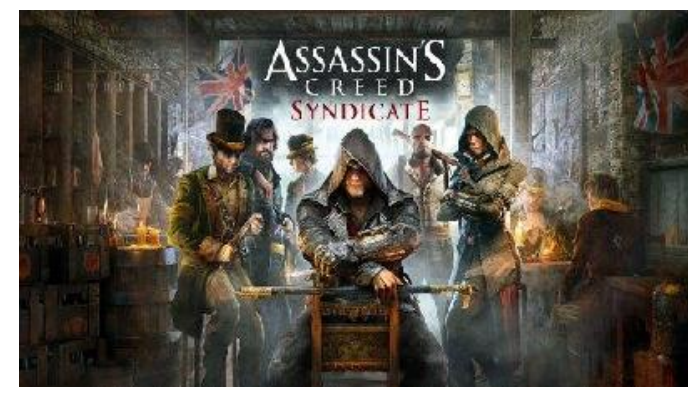

Gambar 2. Banner Assassin's Creed Syndicate Jack the Ripper. (Sumber: http:// terminalgamer.com /2015/12/15/28970/, diakses 17 November 2020)

Assassin's Creed Syndicate - Jack the Ripper versi animasi $360^{\circ}$ merupakan trailer promosi untuk versi gamenya yang dibuat oleh Ubisoft. Dalam versi ini, cerita ditampilkan secara parsial yaitu saat adegan penyerangan Jack The Ripper di tengah Kota London. Hubungan yang rumit antara para Assasin dan Jack The Ripper membuat Jack membunuh anggota Assasin satu per satu. Evie Frye kembali dari India setelah 20 tahun meninggalkan London untuk berhubungan dengan Inspector Frederick Abberline dari Skotlandia untuk memburu Jack dan membalas kerusakan yang telah disebabkannya. Animasi ini mengambil setting Kota London di tahun 1888. Pada saat itu Kota London dihantui oleh adanya 
pembunuh berantai yang dikenal dengan julukan Jack The Ripper.

\begin{tabular}{|c|c|}
\hline $\begin{array}{l}\text { KARAK- } \\
\text { TERISTIK }\end{array}$ & KETERANGAN \\
\hline $\begin{array}{c}\text { Jenis } \\
\text { Animasi }\end{array}$ & $360^{\circ}$ (Virtual Reality) \\
\hline Teknik & 3 Dimensi \\
\hline Storytelling & Narrative \\
\hline $\begin{array}{c}\text { Sudut } \\
\text { Pandang }\end{array}$ & $\begin{array}{c}\text { Orang Kedua dan Orang } \\
\text { Pertama }\end{array}$ \\
\hline Cerita & $\begin{array}{l}\text { Jack The Ripper membunuh } \\
\text { salah satu anggota Assassin di } \\
\text { laboratorium forensik. Tim } \\
\text { Detektif menemukan mayat } \\
\text { korban di tengah jalan dekat } \\
\text { gedung forensik, namun sang } \\
\text { pembunuh yaitu Jack tidak ada } \\
\text { di sana. Jack menyerang } \\
\text { anggota lain di sebuah kamar } \\
\text { apartemen. User menjadi } \\
\text { anggota yang dibunuh ini. }\end{array}$ \\
\hline Karakter & $\begin{array}{c}\text { Jack The Ripper, Anggota } \\
\text { Assassin 1, } 3 \text { Orang Detektif, } \\
\text { dan User sebagai Anggota } \\
\text { Assassin } 2\end{array}$ \\
\hline Plot/Alur & Maju, linier \\
\hline Setting & $\begin{array}{l}\text { Whitechapel, London, saat } \\
\text { malam hari }\end{array}$ \\
\hline $\begin{array}{c}\text { Camera } \\
\text { Movement }\end{array}$ & $\begin{array}{c}\text { Follow Subject, Subjective and } \\
\text { Objective Camera }\end{array}$ \\
\hline
\end{tabular}

Tabel 1 Karakteristik Assassin'sCred Syndicate - Jack the Ripper

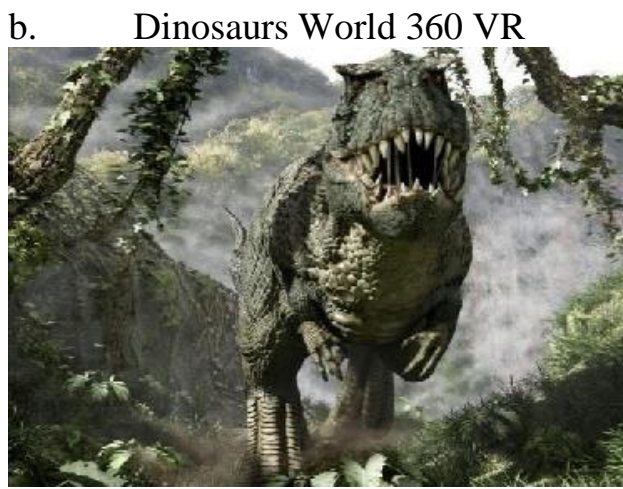

Gambar 3. Screenshot Dinosaurs World 360 VR. (Sumber: $\quad$ https://www.youtube.com/watch?v= luSR3pYPjeI, diakses 17 November 2020)

Dinosaurs World 360 VR adalah sebuah animasi simulasi VR untuk menjelajah zaman prasejarah yang masih dikelilingi oleh kehidupan para dinosaurus. Dalam animasi ini, user seolah berada di dalam kendaraan berbentuk lonjong terbuat dari besi dan sebagian kaca untuk melihat pemandangan. User diajak berkeliling hutan yang terdapat banyak dinosaurus berlalu lalang. Animasi ini dibuat oleh Amazing 360 Studio untuk menciptakan sensasi perjalan ke jaman pra sejarah yang lebih immersive dan menegangkan.

\begin{tabular}{|c|c|}
\hline $\begin{array}{c}\text { KARAK- } \\
\text { TERISTI } \\
\text { K }\end{array}$ & KETERANGAN \\
\hline $\begin{array}{c}\text { Jenis } \\
\text { Animasi }\end{array}$ & $360^{\circ}$ (Virtual Reality) \\
\hline Teknik & 3 Dimensi \\
\hline $\begin{array}{c}\text { Storytellin } \\
g\end{array}$ & Narrative \\
\hline $\begin{array}{c}\text { Sudut } \\
\text { Pandang }\end{array}$ & Orang Pertama \\
\hline Cerita & $\begin{array}{l}\text { User berada di dalam sebuah } \\
\text { kendaraan mengelilingi hutan pra } \\
\text { sejarah. Kemudian user bertemu } \\
\text { dengan Raptor yang ingin mencuri } \\
\text { telur T-rex. Tiba-tiba muncul T-rex } \\
\text { yang memburu Raptor hingaa } \\
\text { membuat user terjatuh ke dalam } \\
\text { jurang dan bertemu dengan kawanan } \\
\text { Pterodactyle. Kendaraan user } \\
\text { berada diatas salah satu Pterodactyle } \\
\text { dan menjelajah savannah yang } \\
\text { terlihat banyak kawanan dinosaurus } \\
\text { lainnya. User terjatuh ke dalam } \\
\text { gerombolan Brontosaurus hingga } \\
\text { akhirnya terinjak oleh salah satu } \\
\text { Brontosaurus. }\end{array}$ \\
\hline Karakter & $\begin{array}{l}\text { Capung, Raptor, T-Rex, } \\
\text { Pterodactyle, Brontosaurus }\end{array}$ \\
\hline Plot/Alur & Maju, linier \\
\hline
\end{tabular}




\begin{tabular}{|c|c|}
\hline Setting & $\begin{array}{c}\text { Hutan, jurang, dan savannah di } \\
\text { jaman prasejarah saat siang hari }\end{array}$ \\
\hline $\begin{array}{c}\text { Camera } \\
\text { Movement }\end{array}$ & Follow Subject, Subjective Camera \\
\hline
\end{tabular}

Tabel 2. Karakteristik Dinosaurs World 360 VR

c. Dunkirk 'Save Every Breath'

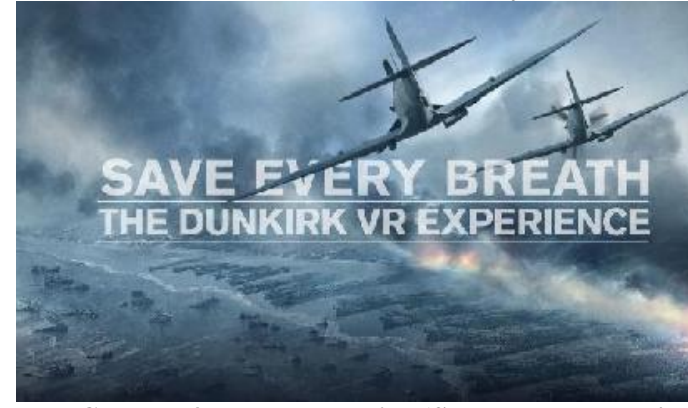

Gambar 4. Banner Dunkirk 'Save Every Breath'. (Sumber: https://littlstar.com/videos/1f0405b0, diakses 17 November 2020)

Dunkirk 'Save Every Breath' merupakan simulasi pengalaman virtual yang membawa user ke dalam suasana Perang Dunia II. User seolah menjadi salah satu prajurit yang berada di medan peperangan. Dalam animasi ini user dihadapkan pada situasi yang mencengangkan dalam perang seperti berlarian di medan perang, dibom, hingga meninggal di dalam air. Dunkirk 'Save Every Breath' versi VR ini merupakan trailer film Dunkirk yang dirilis pada tahun 2017. Dunkirk 'Save Every Breath' dirilis terlebih dahulu sebelum filmnya. Hal ini bertujuan untuk memberikan sensasi perang yang lebih nyata sebelum menonton versi filmnya sehingga penonton akan terbawa dalam imaji perang yang menegangkan.

\begin{tabular}{|c|c|}
\hline $\begin{array}{l}\text { KARAK- } \\
\text { TERISTIK }\end{array}$ & KETERANGAN \\
\hline $\begin{array}{c}\text { Jenis } \\
\text { Animasi }\end{array}$ & $360^{\circ}$ (Virtual Reality) \\
\hline Teknik & 3 Dimensi \\
\hline Storytelling & Narrative \\
\hline $\begin{array}{c}\text { Sudut } \\
\text { Pandang }\end{array}$ & $\begin{array}{c}\text { Orang Pertama (3 Point of } \\
\text { View) }\end{array}$ \\
\hline
\end{tabular}

\begin{tabular}{|c|c|}
\hline Cerita & $\begin{array}{l}\text { User menjadi salah satu tentara } \\
\text { Inggris yang terkepung di } \\
\text { daerah pesisir Dunkirk oleh } \\
\text { pasukan Perancis dan Jerman } \\
\text { saat Perang Dunia II. User } \\
\text { tenggelam di Selat Dover } \\
\text { bersama tentara Inggris lainnya. } \\
\text { User mengendarai pesawat } \\
\text { tempur dan terjatuh ke Selat } \\
\text { Dover. User berada di Dermaga } \\
\text { Dunkirk bersama pasukan } \\
\text { Inggris yang terkepung, hinga } \\
\text { sebuah bom menghantamnya. }\end{array}$ \\
\hline Karakter & Tentara Inggris \\
\hline Plot/Alur & $\begin{array}{c}\text { Maju dari berbagai sudut } \\
\text { pandang di waktu yang } \\
\text { bersamaan, linier }\end{array}$ \\
\hline Setting & $\begin{array}{c}\text { Dermaga Dunkirk, Selat Dover, } \\
\text { saat sore hari }\end{array}$ \\
\hline $\begin{array}{c}\text { Camera } \\
\text { Movement }\end{array}$ & $\begin{array}{c}\text { Follow Subject, Subjective } \\
\text { Camera }\end{array}$ \\
\hline
\end{tabular}

4. Analisis

a. Analisis Assassin's Creed Syndicate - Jack the Ripper
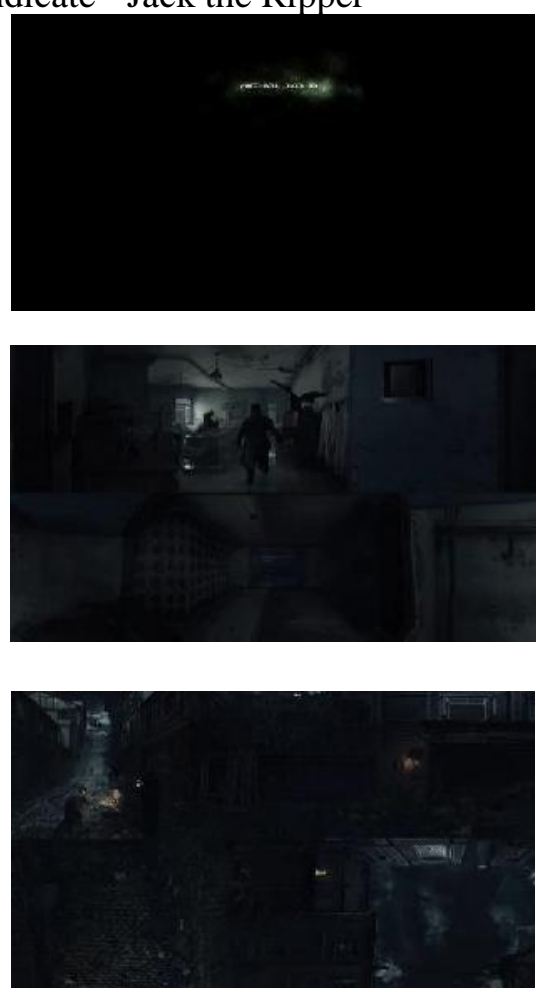

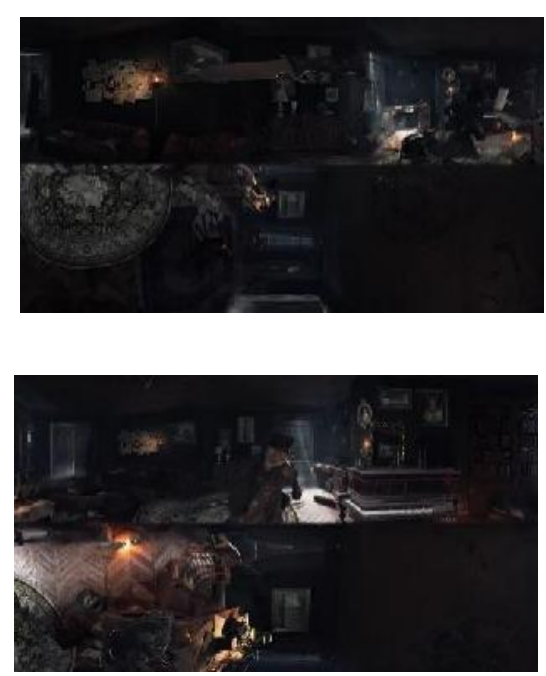

Gambar 5. Screenshot Assasin's Creed Syndicate- Jack the Ripper.

Tabel 4. Analisis Assassin's Creed Syndicate- Jack the

\begin{tabular}{|c|c|c|}
\hline \multicolumn{3}{|c|}{ Ripper. } \\
\hline $\begin{array}{c}\text { Aspek } \\
\text { Review }\end{array}$ & $\begin{array}{c}\text { S } \\
\text { ko } \\
\mathbf{r} \\
(1 \\
- \\
5)\end{array}$ & Review \\
\hline $\begin{array}{c}\text { Pergerakan } \\
\text { Karakter }\end{array}$ & 4 & $\begin{array}{lr}\text { Pergerakan } & \text { karakter } \\
\text { terlihat cukup dinamis } \\
\text { diikuti dengan efek-efek } \\
\text { slow motion yang } \\
\text { memberikan nilai } \\
\text { dramatisasi yang kuat. }\end{array}$ \\
\hline $\begin{array}{l}\text { Ekspresi } \\
\text { Karakter }\end{array}$ & 3 & $\begin{array}{l}\text { Karakter tidak terlalu } \\
\text { banyak menampilkan } \\
\text { perubahan ekspresi. } \\
\text { Misalnya saat Jack The } \\
\text { Reaper mendatangi salah } \\
\text { satu anggota Assassin, } \\
\text { tidak terlihat ekspresi } \\
\text { terkejut dari raut muka } \\
\text { Assassin, hanya terlihat } \\
\text { ekspresi takut yang sama } \\
\text { dari sejak didatangi } \\
\text { hingga dibunuh oleh Jack } \\
\text { The Reaper. }\end{array}$ \\
\hline $\begin{array}{c}\text { Sinematogr } \\
\text { afi }\end{array}$ & 5 & $\begin{array}{l}\text { Tata cahaya berhasil } \\
\text { membuat suasana dalam } \\
\text { scene lebih mencekam. } \\
\text { Hal ini juga didukung } \\
\text { dengan pengambilan } \\
\text { sudut pandang yang tepat. }\end{array}$ \\
\hline Storytelling & 2 & $\begin{array}{l}\text { Penyampaian pesan } \\
\text { dalam cerita tidak begitu } \\
\text { jelas akibat pergerakan } \\
\text { Jack The Reaper yang } \\
\text { begitu cepat, sementara } \\
\text { kamera terus bergerak } \\
\text { sehingga } \text { user tidak diberi } \\
\text { kesempatan untuk }\end{array}$ \\
\hline
\end{tabular}

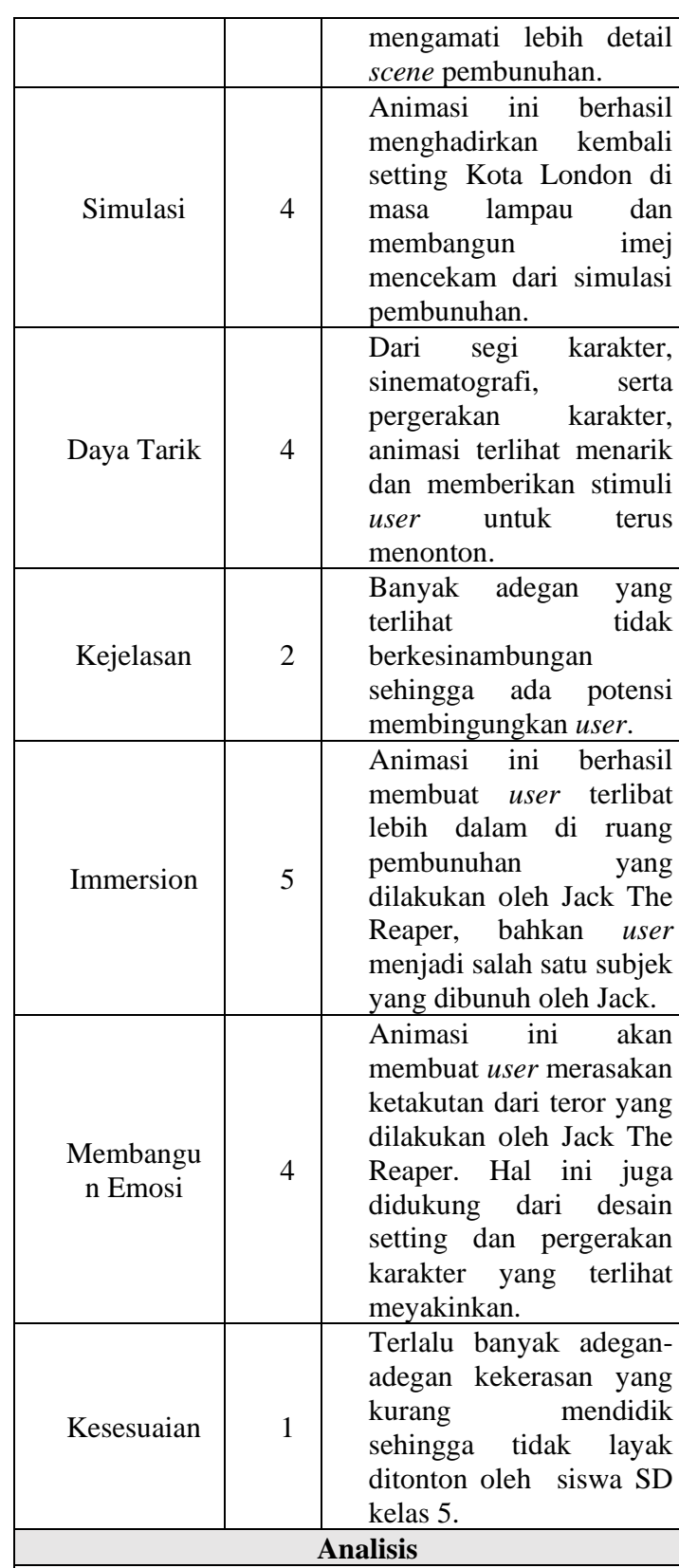

\section{Kelebihan:}

Animasi ini berhasil menyajikan ruang simulasi atas teror yang dilakukan oleh Jack The Reaper dalam aksinya memburu para anggota Assasin di London tahun 1888. Hal ini didukung dari pergerakan karakter dan sinematografi yang terlihat meyakinkan sehingga menimbulkan daya tarik tertentu dan membangun emosi ketakutan.

\section{Kekurangan:}

Namun sayangnya ekspresi karakter kurang dinamis dan masih banyak adegan yang tidak berkesinambungan sehingga cerita sulit dipahami oleh siswa SD kelas 5. Di samping itu adeganadegan kekerasan yang ditampilkan dalam animasi membuatnya tidak sesuai untuk siswa Sd kelas 5. 

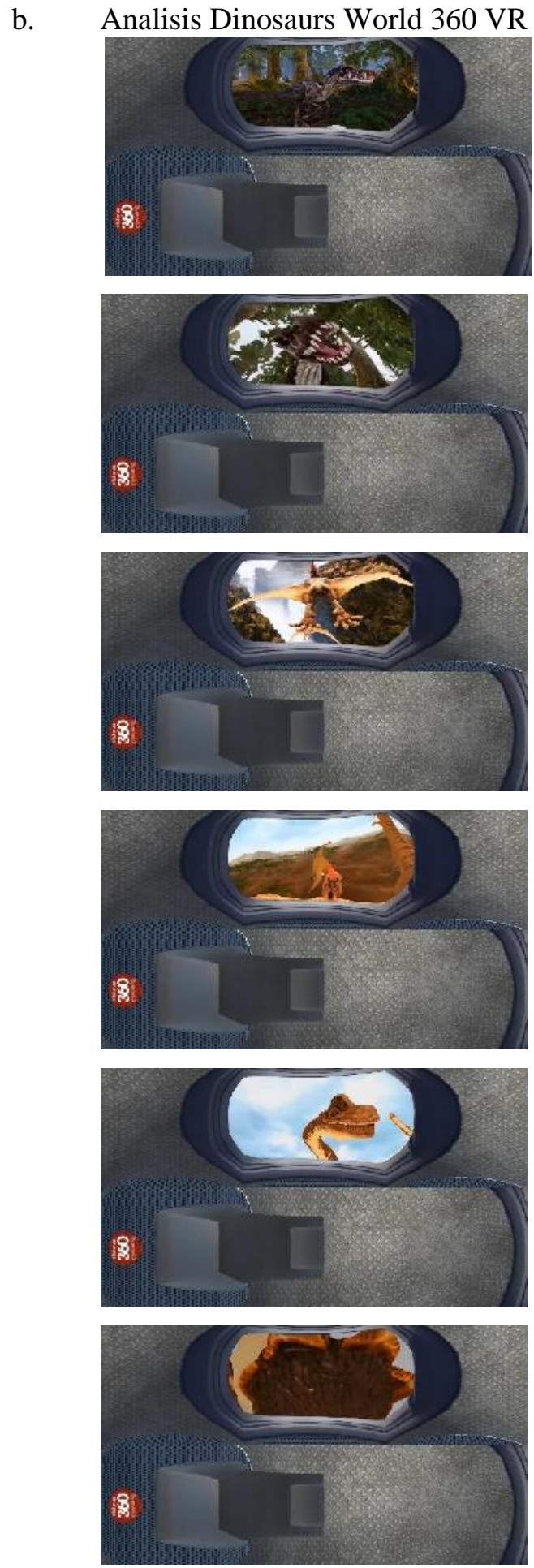

Gambar 6. Screenshot Dinosaurs World 360 VR.

Tabel 5. Analisis Dinosaurs World 360 VR.

\begin{tabular}{|c|c|c|}
\hline $\begin{array}{c}\text { Aspek } \\
\text { Review }\end{array}$ & $\begin{array}{c}\text { Sk } \\
\text { or } \\
(\mathbf{1 -}\end{array}$ & Review \\
\hline $\begin{array}{c}\text { Pergerakan } \\
\text { Karakter }\end{array}$ & 4 & $\begin{array}{c}\text { Pergerakan dinosaurus } \\
\text { sudah terlihat meyakinkan }\end{array}$ \\
\hline
\end{tabular}

\begin{tabular}{|c|c|c|}
\hline & & $\begin{array}{l}\text { walaupun terlihat kurang } \\
\text { smooth. }\end{array}$ \\
\hline $\begin{array}{l}\text { Ekspresi } \\
\text { Karakter }\end{array}$ & 2 & $\begin{array}{l}\text { Ekspresi dinosaurus } \\
\text { kurang memberikan } \\
\text { stimuli emosi yang kuat } \\
\text { akibat dinamika perubahan } \\
\text { ekspresi yang jarang } \\
\text { terlihat. }\end{array}$ \\
\hline $\begin{array}{c}\text { Sinematograf } \\
\mathrm{i}\end{array}$ & 3 & $\begin{array}{l}\text { Tata cahaya kurang baik } \\
\text { akibat eksplorasi warna } \\
\text { cahaya masih terlihat } \\
\text { kurang kuat untuk } \\
\text { membangun situasi yang } \\
\text { lebih mencekam di jaman } \\
\text { pra sejarah. Namun, sudut } \\
\text { pandang yang ditampilkan } \\
\text { terlihat sangat menarik } \\
\text { karena secara garis besar, } \\
\text { user selalu dalam posisi } \\
\text { worm eye level di antara } \\
\text { dinosaurus yang besar- } \\
\text { besar. }\end{array}$ \\
\hline Storytelling & 4 & $\begin{array}{l}\text { Pesan cerita disampaikan } \\
\text { dengan cara yang cukup } \\
\text { baik meskipun cerita } \\
\text { berakhir tragis ketika } \text { user } \\
\text { sebagai tokoh utama } \\
\text { hancur terinjak } \\
\text { brontosaurus. }\end{array}$ \\
\hline Simulasi & 3 & $\begin{array}{l}\text { Dunia jaman prasejarah } \\
\text { cukup baik disajikan } \\
\text { dalam lingkungan virtual } \\
\text { reality meskipun suasana } \\
\text { kurang dibangun lebih } \\
\text { mencekam akibat tata } \\
\text { cahaya yang kurang } \\
\text { diperkuat dan ekspresi } \\
\text { dinosaurus yang kurang } \\
\text { dinamis. }\end{array}$ \\
\hline Daya Tarik & 3 & $\begin{array}{l}\text { Secara garis besar animasi } \\
\text { ini cukup menarik bagi } \\
\text { seseorang yang ingin } \\
\text { melakukan touring ke } \\
\text { jaman dinosaurus. Namun } \\
\text { kurangnya eksplorasi } \\
\text { ekpresi karakter dan tata } \\
\text { cahaya membuat situasi } \\
\text { kurang meyakinkan. }\end{array}$ \\
\hline Kejelasan & 4 & $\begin{array}{l}\text { Secara garis besar adegan } \\
\text { ditampilkan dengan cukup } \\
\text { jelas sehingga pesan bisa } \\
\text { tersampaikan dengan lebih } \\
\text { baik. }\end{array}$ \\
\hline Immersion & 3 & $\begin{array}{l}\text { User cukup terlibat lebih } \\
\text { dalam di dunia dinosaurus } \\
\text { dengan menjadi peserta } \\
\text { tour, namun situasi yang } \\
\text { seharusnya mencekam } \\
\text { terlihat } \\
\text { meyakinkan. }\end{array}$ \\
\hline $\begin{array}{l}\text { Membangun } \\
\text { Emosi }\end{array}$ & 3 & $\begin{array}{l}\text { Emosi ketakutan yang } \\
\text { dibangun kurang begitu } \\
\text { kuat dan meyakinkan, } \\
\text { namun berbagai situasi }\end{array}$ \\
\hline
\end{tabular}




\begin{tabular}{|c|c|c|}
\hline & & $\begin{array}{l}\text { yang dialami oleh user } \\
\text { cukup membuat user } \\
\text { merasakan sensasi tegang } \\
\text { terutama saat jatuh dari } \\
\text { atas tebing. }\end{array}$ \\
\hline Kesesuaian & 4 & $\begin{array}{lr}\text { Animasi ini cukup sesuai } \\
\text { untuk ditonton oleh siswa } \\
\text { SD kelas } 5 \text { karena tidak } \\
\text { mengandung } \\
\text { kekerasan yang jelas } \\
\text { terlihat. }\end{array}$ \\
\hline \multicolumn{3}{|c|}{ Analisis } \\
\hline \multicolumn{3}{|c|}{$\begin{array}{l}\text { Kelebihan: } \\
\text { Pergerakan karakter, sudut pandang kamera, } \\
\text { kejelasan cerita, dan strategi storytelling yang cukup } \\
\text { baik memberikan pengalaman menjelajah dunia } \\
\text { dinosaurus di jaman pra sejarah yang cukup } \\
\text { berkesan. Selain itu konten yang ditampilkan sudah } \\
\text { sesuai untuk siswa SD kelas 5. }\end{array}$} \\
\hline \multicolumn{3}{|c|}{$\begin{array}{l}\text { Kurangnya eksplorasi ekspresi karakter serta tata } \\
\text { cahaya membuat ruang simulasi kurang meyakinkan } \\
\text { dan immersive sehingga emosi ketakutan user belum } \\
\text { cukup terbangun. }\end{array}$} \\
\hline
\end{tabular}

c. Analisis Dunkirk 'Save Every Breath'
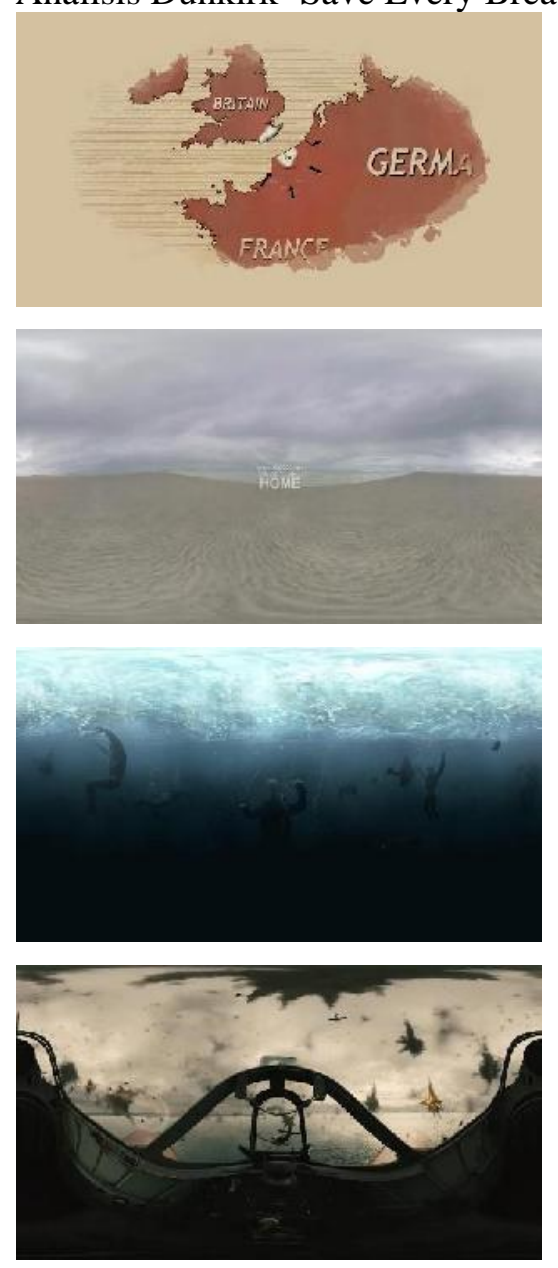
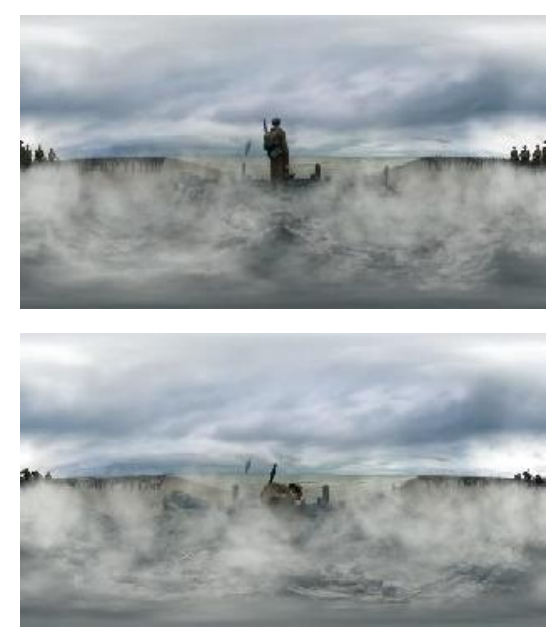

Gambar 7. Screenshot Dunkirk 'SaveEvery Breath'.

Tabel 6. Analisis Dunkirk ‘SaveEvery Breath’.

\begin{tabular}{|c|c|c|}
\hline $\begin{array}{l}\text { Aspek } \\
\text { Review }\end{array}$ & $\begin{array}{l}\text { Skor } \\
(1-5)\end{array}$ & Review \\
\hline $\begin{array}{l}\text { Pergerakan } \\
\text { Karakter }\end{array}$ & 2 & 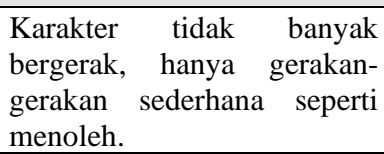 \\
\hline $\begin{array}{l}\text { Ekspresi } \\
\text { Karakter }\end{array}$ & 1 & $\begin{array}{l}\text { Ekspresi karakter tidak begitu } \\
\text { terlihat jelas, padahal dalam } \\
\text { situasi perang yang } \\
\text { seharusnya nampak emosi } \\
\text { ketakutan ataupun semangat } \\
\text { perjuangan. }\end{array}$ \\
\hline Sinematografi & 5 & $\begin{array}{l}\text { Scene Perang Dunia II } \\
\text { ditampilkan dengan sangat } \\
\text { realistis dan meyakinkan } \\
\text { melalui tata cahaya, desain } \\
\text { medan perang, serta efek } \\
\text { yang memberikan kesan } \\
\text { situasi perang yang dalam. }\end{array}$ \\
\hline Storytelling & 2 & $\begin{array}{l}\text { Pesan cerita tidak } \\
\text { tersampaikan dengan baik } \\
\text { akibat penggunan plot yang } \\
\text { tidak biasa. User menjadi } \\
\text { sosok dan sudut pandang } \\
\text { yang berbeda dalam waktu } \\
\text { yang bersamaan, sehingga } \\
\text { butuh usaha lebih jauh untuk } \\
\text { memahami isi cerita. }\end{array}$ \\
\hline Simulasi & 4 & $\begin{array}{l}\text { Pada dasarnya simulasi } \\
\text { Perang Dunia II sudah baik } \\
\text { disajikan dalam animasi ini } \\
\text { meskipun kurang kuat } \\
\text { dibangun secara emosional } \\
\text { melalui pergerakan dan } \\
\text { ekspresi karakter. }\end{array}$ \\
\hline Daya Tarik & 3 & $\begin{array}{l}\text { Penggunaan plot yang tidak } \\
\text { biasa memiliki nilai daya } \\
\text { tarik tersendiri meskipun } \\
\text { berpotensi menimbulkan } \\
\text { ambigu dari sisi pemaknaan } \\
\text { pesan cerita. }\end{array}$ \\
\hline Kejelasan & 2 & $\begin{array}{l}\text { Pesan tidak tersampaikan } \\
\text { cukup jelas sehingga perlu }\end{array}$ \\
\hline
\end{tabular}




\begin{tabular}{|c|c|c|}
\hline & & $\begin{array}{l}\text { usaha yang lebih jauh untuk } \\
\text { memahami isi ceritanya. }\end{array}$ \\
\hline Immersion & 3 & $\begin{array}{l}\text { Keterlibatan } \text { user agar dapat } \\
\text { lebih dalam masuk ke dalam } \\
\text { ruang simulasi Perang Dunia } \\
\text { II sudah cukup baik } \\
\text { ditampilkan } \\
\text { kurangnya meskipun } \\
\text { dibangun. }\end{array}$ \\
\hline $\begin{array}{l}\text { Membangun } \\
\text { Emosi }\end{array}$ & 2 & $\begin{array}{l}\text { Emosi yang dibangun kurang } \\
\text { begitu meyakinkan dan jelas } \\
\text { akibat pergerakan dan } \\
\text { ekspresi karakter yang } \\
\text { kurang dinamis. }\end{array}$ \\
\hline Kese & 3 & $\begin{array}{l}\text { Secara konten, animasi ini } \\
\text { sudah cukup sesuai bagi } \\
\text { siswa SD kelas } 5 \text { karena } \\
\text { adegan-adegan kekerasan } \\
\text { berhasil ditampilkan secara } \\
\text { tersirat. Namun gaya realis } \\
\text { yang menjadi konsep animasi } \\
\text { ini tidak terlalu sesuai bagi } \\
\text { siswa SD kelas 5. }\end{array}$ \\
\hline \multicolumn{3}{|c|}{ Analisis } \\
\hline \multicolumn{3}{|c|}{$\begin{array}{l}\text { Kelebihan: } \\
\text { Animasi Dunkirk 'Save Every Breath' menampilkan } \\
\text { simulasi Perang Dunia II yang cukup meyakinkan } \\
\text { melalui sinematografi yang baik. Secara konten sudah } \\
\text { cukup sesuai bagi siswa SD kelas } 5 \text {. }\end{array}$} \\
\hline \multicolumn{3}{|c|}{$\begin{array}{l}\text { Animasi Dunkirk 'Save Every Breath' kurang } \\
\text { membangun emosi user ketika dalam situasi perang } \\
\text { akibat kurangnya dinamika pergerakan dan ekspresi } \\
\text { karakter. Selain itu penggunaan plot yang tidak biasa } \\
\text { berpotensi membuat rancu pesan yang ingin } \\
\text { disampaikan. }\end{array}$} \\
\hline
\end{tabular}

\section{d. Analisis Perbandingan}

Secara garis besar animasi Assassin's Creed Syndicate - Jack the Ripper, Dinosaurs World 360 VR, serta Dunkirk 'Save Every Breath' memiliki kesamaan dari segi teknik dan pergerakan kamera. Teknik yang digunakan yaitu animasi 3 dimensi, sementara pergerakan kamera selalu follow subject baik sebagai objektif maupun subjektif kamera. Animasi Assassin's Creed Syndicate - Jack the Ripper dan Dinosaurs World 360 VR memiliki kesamaan alur yaitu maju dengan plot yang linier. Di sisi lain animasi Dunkirk 'Save Every Breath' memiliki alur yang berbeda yaitu maju tapi dari berbagai sudut pandang dalam waktu yang bersamaan, namun plot yang digunakan masih tergolong linier. Strategi storytelling yang digunakan adalah narrative storytelling yang memaparkan situasi dari waktu ke waktu. Sudut pandang yang paling umum digunakan adalah sudut pandang orang pertama. Jenis sudut pandang ini membuat user menjadi salah satu subjek dalam animasi tersebut.

Dari segi pergerakan karakter, animasi Assassin's Creed Syndicate - Jack the Ripper sama baiknya dengan Dinosaurs World 360 VR. Animasi Dunkirk 'Save Every Breath' adalah yang terburuk dibandingkan kedua animasi lainnya. Hal ini dikarenakan kedua animasi tersebut berhasil menampilkan pergerakan karakter yang lebih dinamis.

Dari sisi ekspresi karakter, animasi Dunkirk 'Save Every Breath' adalah yang terburuk di antara keduanya. Animasi Dinosaurs World 360 VR menampilkan ekspresi karakter yang lebih baik dibandingkan animasi Dunkirk 'Save Every Breath'. Animasi Assassin's Creed Syndicate - Jack the Ripper adalah yang terbaik di antara ketiganya karena menampilkan ekspresi yang bisa membangun emosi user.

Sinematografi animasi Dunkirk 'Save Every Breath' dan Assassin's Creed Syndicate - Jack the Ripper lebih baik dibandingkan animasi Dinosaurs World 360 VR. Hal ini dikarenakan kedua animasi tersebut berhasil menyajikan tata cahaya dan sudut pandang yang berhasil menghidupkan suasana di masa lampau dan membangun emosi sesuai tujuan animasi.

Namun dari sisi storytelling, animasi Dinosaurs World 360 VR adalah yang terbaik di antara keduanya. Hal ini dikarenakan animasi ini berhasil menyampaikan pesan cerita dengan lebih jelas dan mudah diterima oleh penonton. Animasi Assassin's Creed Syndicate - Jack the Ripper dan Dunkirk 'Save Every Breath menampilkan celah-celah kesinambungan adegan yang berpotensi membingungkan user dalam memaknainya.

Animasi Assassin's Creed Syndicate Jack the Ripper dan Dunkirk 'Save Every Breath' berhasil menyajikan ruang simulasi yang lebih baik dibandingkan animasi Dinosaurs World 360 VR. Hal ini disebabkan oleh faktor sinematografi yang 
dibangun dalam kedua animasi tersebut, masing-masing berhasil menampilkan setting sejarah yang meyakinkan. Kekuatan animasi Assassin's Creed Syndicate - Jack the Ripper terletak pada penggunaan tata cahaya yang kuat, sementara animasi unkirk 'Save Every Breath' lebih kuat dalam membangun tata cahaya yang realistis.

Animasi Assassin's Creed Syndicate Jack the Ripper adalah yang paling menarik diantara ketiganya. Hal ini disebabkan oleh desain karakter, pergerakan karakter, dan sinematografi yang baik sehingga user bisa bertahan lebih lama untuk terus menontonnya.

Dari segi kejelasan, animasi Dinosaurs World 360 VR adalah yang paling jelas karena perpindahan dari scene ke scene berjalan dengan linier sehingga tidak ada celah adegan yang berpotensi membingungkan user.

Ditinjau dari sisi immersion, animasi Assassin's Creed Syndicate - Jack the Ripper adalah yang paling immersive. Animasi ini berhasil membuat user terlibat lebih dalam di ruang pembunuhan yang dilakukan oleh Jack The Reaper, bahkan user menjadi salah satu subjek yang dibunuh oleh Jack.

Dari ketiganya, animasi Assassin's Creed Syndicate - Jack the Ripper adalah yang paling sukses membangun emosi penonton terutama emosi ketakutan akibat situasi yang mencekam dari teror yang dilakukan oleh Jack The Reaper. Hal ini juga didukung dari desain setting dan pergerakan karakter yang terlihat meyakinkan.

Namun jika dikaitkan dengan kalangan pelajar sebagai target usernya, maka konten-konten yang ditampilkan oleh animasi Dinosaurs World 360 VR adalah yang paling sesuai. Hal ini disebabkan oleh faktor kekerasan yang tidak secara jelas diperlihatkan di sini.

5. Rekomendasi

Animasi dengan teknik 3 dimensi merupakan animasi yang sering digunakan untuk animasi $360^{\circ}$ (VR) berkonten sejarah. Teknik ini memungkinkan user untuk mengeksplorasi kedalaman ruang yang lebih nyata.
Penggunaan alur yang paling sesuai untuk animasi sejarah adalah alur maju (linier). Alur ini mampu memberikan gambaran peristiwa kesejarahan dengan lebih jelas sehingga meminimalisir kerancuan pesan. Hal ini seperti yang dicontohkan dalam animasi Assassin's Creed Syndicate - Jack the Ripper dan Dinosaurs World 360 VR. Di sisi lain, teknik storytelling yang tidak umum berpotensi menimbulkan kerancuan pesan dan sulitnya pemahaman materi juga seperti dalam kasus animasi Dunkirk 'Save Every Breath' terutama untuk pelajar. Oleh karena itu teknik storytelling semacam ini sebaiknya dihindari.

Pergerakan karakter yang lebih dinamis akan memberikan suasana belajar sejarah menjadi lebih intens sehingga perhatian siswa tidak akan teralihkan pada hal yang lain. Hal ini juga didukung dengan ekspresi karakter yang lebih dinamis dan meyakinkan agar terjalin ikatan emosi yang kuat antara user dengan tokoh dalam animasi bertema sejarah tersebut.

Penggunaan tata cahaya yang tepat serta pemilihan sudut pandang kamera yang sesuai dalam membangun suasana dan menghidupkan kembali setting kesejarahan akan memberikan sinematografi yang lebih dalam menarik perhatian user. Di samping itu, pengalaman ruang simulasi bertemakan sejarah akan memberikan sensasi menjelajah masa lampau yang lebih terasa nyata.

Adegan yang berhubungan dengan kekerasan sebaiknya ditampilkan secara eksplisit agar konten animasi sejarah lebih sesuai ditonton oleh pelajar. Contohnya pada animasi Dunkirk 'Save Every Breath', secara tidak langsung memperlihatkan bom yang menewaskan banyak tentara melainkan melalui efek cahaya dan asap yang kuat sehingga adegan kekerasan tidak tergambar jelas namun tetap mampu dipahami.

6. Implementasi

Implementasi adalah proses pelaksanaan atau penerapan. Dalam hal ini, hasil-hasil rekomendasi akan diterapkan pada proses perancangan 
kedepannya sehingga hasil perancangan bisa lebih maksimal karena berlandaskan pada hasil perancangan yang sudah ada sebelumnya dengan mengaplikasikan poin-poin kelebihannya dan menghindari poin-poin kekurangannya. Majone dan Wildavsky (dalam Usman, 2002), mengemukakan implementasi sebagai evaluasi. Dalam hal ini selain menerapkan poin-poin rekomendasi juga berusaha mengevaluasi hasil kerja sehingga aspekaspek rekomendasi bisa diterapkan dengan lebih maksimal.

\section{SIMPULAN}

Secara umum, animasi sejarah $360^{\circ}$ menggunakan teknik animasi 3 dimensi. Alur yang digunakan cenderung linier (maju) dengan memakai strategi narrative storytelling. Sudut pandang yang digunakan adalah orang pertama. Pergerakan kamera yang digunakan adalah follow subject baik secara objective maupun subjective camera.

Pergerakan dan ekspresi karakter dalam animasi sejarah akan lebih baik jika ditampilkan secara dinamis. Selain itu penggunaan tata cahaya yang kuat dan realistis serta pemilihan sudut pandang kamera yang tepat mampu memberikan ikatan emosi yang lebih dalam terhadap user. Hal ini juga akan meningkatkan daya tarik user untuk tetap menonton. Ruang simulasi dan tingkat immersion yang terbangun juga akan lebih baik.

Strategi storytelling yang tepat dan kejelasan cerita mampu menyampaikan pesan cerita yang lebih mudah dipahami sehingga materi pembelajaran bisa dicerna dengan lebih baik. Namun perlu dihindari adegan-adegan kekerasan yang secara jelas terlihat agar animasi sejarah bisa lebih sesuai ditonton oleh pelajar.

\section{DAFTAR RUJUKAN}

Agustien, R., Umamah, N., Sumarno, S. 2018. Pengembangan Media Pembelajaran Video Animasi Dua Dimensi Situs Pekauman di Bondowoso Dengan Model Addie Mata Pelajaran Sejarah Kelas X
IPS. Jurnal Edukasi, vol.5, no.1 (hal. 19-23). doi:10.19184/jukasi.v5i1.8010

Ernest Adams. (2004). Postmodernism and the Three Types of Immersion. [online] Available at: http://designersnotebook.com/Col umns/063_Postmodernism/063_po stmodernism.htm [Accessed 5 May. 2017].

Jamil, M. 2018. Pemanfaatan Teknologi Virtual Reality (VR) Di Perpustakaan. Buletin Perpustakaan Universitas Islam Indonesia, vol.1, no.1 (hal. 99113).

Michael Cieply. (2014). Virtual Reality 'Wild' Trek, With Reese Witherspoon. [online] Available at:

https://www.nytimes.com/2014/12 /15/business/media/virtual-realitywild-trek-with-reesewitherspoon.html?_r=0 [Accessed 5 May. 2017].

Noah Nelson. (2015). All VR's a Stage Presence Story and The Birth of The Medium. [online] Available at: https://turnstylenews.com/2015/08 /12/all-vrs-a-stage-presence-storyand-the-birth-of-the-new-medium/ [Accessed 5 May. 2017].

Nechvatal, J. 2009. Immersive Ideals/Critical Distances, Saarbrücken: LAP Lambert Academic Publishing. (hal. 367368).

Pictures, W.B. (n.d.). Save Every Breath: The Dunkirk VR Experience. [online] Littlstar. Available at: https://littlstar.com/videos/1f0405 b0 [Accessed 17 Nov. 2020].

Sayono, J. 2013. Pembelajaran Sejarah di Sekolah: Dari Pragmatis ke Idealis. Jurnal Sejarah dan Budaya, vol.7, no.1 (hal. 9-16). doi:10.17977/sb.v7i1.4733

Sukmawati, Susianto, D. 2019. Perancangan Sistem Pemesanan 
E-Tiket Pada Wisata Di Lampung Berbasis Web Mobil. Jurnal ONESISMIK, vol.2, no.2 (hal. 6071).

Terminal Gamer. (2015). Jack The Ripper Add-On Content For Assassin's Creed Syndicate Now Available Plus a VR Video. [online] Available at: http://terminalgamer.com/2015/12 /15/28970/ [Accessed 17 Nov. 2020].

Usman, N. 2002. Konteks Implementasi Berbasis Kurikulum. Jakarta: PT. Raja Grafindo Persada.

v360 Videos (2017). Dinosaurs World 360 VR. YouTube. Available at: https://www.youtube.com/watch?v $=$ luSR3pYPjeI [Accessed 17 Nov. 2020]. 